\title{
In Vitro Assessment of the Tolerance Profile, the Metabolism and the Potential Depigmenting Activity of New Retinoid Derivatives
}

\author{
Olivier Sorg ${ }^{*}$, Behrooz Kasraee and Jean-Hilaire Saurat
}

University of Geneva, Swiss Centre for Applied Human Toxicology, Geneva, Switzerland

\begin{abstract}
Background: In spite of the numerous depigmenting agents available, there is an inverse relationship between safety and efficiency. Natural retinoids exert depigmenting activities in vivo, but have a narrow therapeutic window. There is thus a need for a new class of depigmenting agents that would be both safe and useful.

Objective: The aim of the study was to analyse the potential interest of new retinoid derivatives as topical depigmenting agents.

Methods: The tolerance profile of the new retinoids was analysed in murine BDVII keratinocytes and murine B16 melanocytes using the MTT assay. The uptake and the metabolism of the retinoids were analysed in keratinocytes and melanocytes by HPLC/UV. The cellular content of melanin was determined in melanocytes using a photometric assay.

Results: Methyl- and $t$-butyl-4-oxoretinoate, arbutin retinoate and retinoic acid were shown to have the best depigmenting potential according to the ratio between the $\mathrm{IC}_{50}$ for $\mathrm{MTT}$ assay and that for melanin content. Retinaldehyde, 4hydroxyretinaldehyde and methyl-4-hydroxyretinoate have a good depigmenting potential too, although the therapeutic window is narrower due to a higher toxicity.

Conclusion: 4-Oxoesters of retinoic acid, arbutin retinoate and 4-hydroxyretinaldehyde derivatives offer a new family of depigmenting agents acting via a different pathway than tyrosinase inhibitors.
\end{abstract}

Keywords: Keratinocytes, melanocytes, metabolism, pharmacology, pigmentation, retinoids.

\section{INTRODUCTION}

The pigmentation of the skin, due to melanin deposits, plays an important role in protecting the skin from the harmful effects of solar UV radiations. However, hyperpigmented lesions of the skin pose a problem to many people beyond a simple question of aesthetics [1-3]. In spite of a high demand, it's still difficult to find a safe and efficient treatment to lighten the skin. Although most of available depigmenting agents are based on their ability to inhibit tyrosinase in vitro, they did not prove to be effective when applied to human skin. Topical formulations shown to have a significant efficacy in some definite situations are not safe, in particular for a long period of time required to reach satisfying results [4, 5]. In this context it would be interesting to find a new class of safe topical depigmenting agents, acting via a different mechanism of action than tyrosinase inhibition.

Besides their known biological actions on morphogenesis, cell growth and differentiation, retinoids may have a depigmenting potential, as some of them have been shown to inhibit the pigmentation of human and animal skin, either alone or in combination with other compounds [6-8]. Retinoids are metabolised by hydroxylation and carbonylation

*Address correspondence to this author at the Swiss Centre for Applied Human Toxicology (SCAHT), University of Geneva, 1 rue Michel-Servet, CH-1211 Geneva, Switzerland; Tel: 004122379 5032;

Fax: 004122379 5502; E-mail: olivier.sorg@unige.ch in position 4 of the cyclohexenyl cycle and by conjugation to glucuronate [9-11]. This oxidation does not abolish their biological activity, as demonstrated in a previous study in mice, where 4-oxoretinaldehyde, and to a lesser extent and 4oxoretinol, were shown to have a lower but significant biological activity than their unmetabolised precursors [12]. On the other hand it seems that esterification of retinoic acid is not an endogenous process. Some retinoate esters have been synthesised in order to increase the stability or the chemopreventive property of retinoic acid [13], but these derivatives did not lead to a new family of therapeutic retinoids.

In this study we analysed in cell cultures the tolerance profile and the effects on cellular melanin of a new family of retinoids derived from 4-oxygenated forms of retinaldehyde and retinoic acid esterified to arbutin or fatty acids (Fig. 1).

\section{MATERIALS AND METHODS}

\section{Chemicals}

All retinoids, except all trans-retinoic acid (RA), all tansretinaldehyde (RAL), and all-trans retinol (ROL), were provided by Pierre Fabre Dermo-Cosmétique (Toulouse, France). The other chemicals, if not specified differently, were purchased from Sigma (Buchs, Switzerland).

\section{Monolayer Cell Cultures}

Murine B16 melanocytes and BDVII keratinocytes, as well as human A431 cells, were cultured as previously 
described [14, 15]. Briefly, both BDVII and A431 keratinocytes were grown on DMEM FCS $10 \%$, and B16 melanocytes were grown in the same medium supplemented with $1 \mathrm{~nm}$ cholera toxin (Gentaur, Brussels, Belgium). Both media contained $100 \mathrm{U} / \mathrm{ml}$ penicillin $\mathrm{G}$ and $100 \mu \mathrm{g} / \mathrm{ml}$ streptomycin (Invitrogen, Basel, Switzerland). Cells were plated at 20'000 cells per well in 24-well plates and grown until confluence (3-4 days). The tested compounds were dissolved in ethanol and added to the cultures at the final indicated concentrations in 1\% ethanol. This procedure was repeated daily for three consecutive days, then on day 5 cell viability was assessed using the MTT assay and melanin content determined spectrophotometrically as described below.

\section{Melanin Determination}

Cell cultures and reconstructed epidermis were rinsed with phosphate buffered saline (PBS), treated with trypsin $0.05 \%$-EDTA for 10 minutes at $37^{\circ} \mathrm{C}$ or with trypsin $0.83 \%$ for one hour at $37^{\circ} \mathrm{C}$, respectively, then melanin was extracted and its content determined spectrophotometrically at $405 \mathrm{~nm}$ and normalised by MTT assay as previously described [16].

\section{Retinoid Analysis}

Retinoids were applied at $10 \mu \mathrm{M}$ for 4,24 or 96 hours in BDVII keratinocytes or B16 melanocytes, then the cells were lysed and harvested by sonication in $50 \mathrm{mM}$ acetate buffer $\mathrm{pH} \mathrm{4}$, and intracellular retinoids were analysed by high performance liquid chromatography (HPLC) and UV detection as described (Table 1) [17]. Results shown in Figs.
(2-5) are expressed as (pmol retinoid/mg protein) and represent the means of duplicate experiments performed in the same series of culture. The whole experiments were repeated twice in two separate series of cultures with similar pharmacological profiles, although with different absolute values due to inter-experiment variability.

\section{DOPA Oxidase Activity}

DOPA oxidase activity (tyrosinase activity) was determined as previously described [14]. Briefly cultured B16 melanocytes were treated each day for 4 days by various concentrations of tested retinoids, then cells were harvested and DOPA oxidase activity was determined spectrophotometrically by the MBTH (3-methyl-2-benzothiazolinone hydrazone) assay [18].

\section{Photometric Analyses}

Retinoid derivatives were dissolved in ethanol to prepare $10 \mu \mathrm{M}$ solutions, whereas arbutin was dissolved at $100 \mu \mathrm{M}$ in water; $200 \mu \mathrm{l}$ of these solutions were transferred into 96well UV-STAR microplates (Greiner Bio One, Reinach, Switzerland), then absorption spectra were performed to determine the highest absorbance wavelength using an EnVision multiplate reader (Perkin Elmer, Schwerzenbach, Switzerland). For each solution, the absorbance was read at the respective maximum wavelength, and the molar extinction coefficient $(\varepsilon)$ was calculated using the BeerLambert formula: $\varepsilon=\mathrm{A} / \ell \cdot \mathrm{c}$, where $\mathrm{A}$ is the absorbance, $\ell$ the height of the solution in the microplate $(0.56 \mathrm{~cm})$ and $\mathrm{c}$ the molar concentration.

Table 1. Names and Spectral Parameters of the Tested Compounds

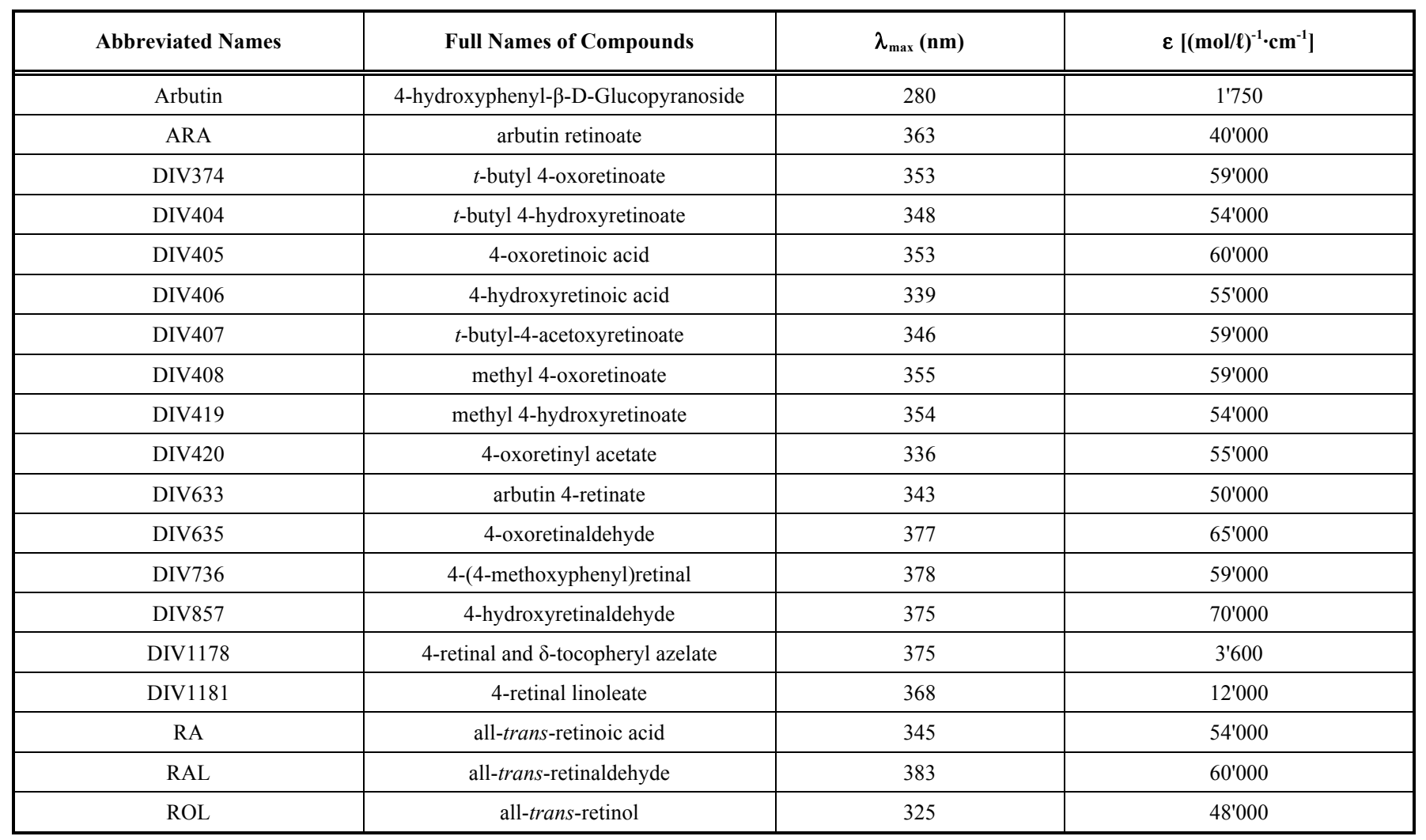


RA<smiles>CC(=CC=CC=C(C)C1(C)CCCCC1(C)C)CC=CC(=O)O</smiles>

DIV405<smiles>CC1=CCC(=O)C(C)=C1/C=C(C)/C=C/C=C/C(C)=C/C(=O)O</smiles>

DIV406<smiles>CC(C)=CC=CC=CC(C)=CC=CC(=O)O</smiles>

DIV374<smiles>CC(C)=CC(=O)OC(C)(C)C</smiles>

DIV404<smiles>CC(C)=CC=CC(C)=CC=CC(=O)OC(C)(C)C</smiles>

DIV408<smiles>COC(=O)/C=C/C=C/C=C/C(C)=C/C=C1C(=O)CCC(C)=C1C</smiles>

DIV419<smiles>COC(=O)/C=C/C=C/C=C/C(C)=C/C=C1C(C)=C(C)CCC1O</smiles>

RAL<smiles>CC1=C(/C=C(C)/C=C/C=C(C)/C=C/C=O)C(C)(C)CCC1</smiles>

DIV635<smiles>CC(C)=CC=CC=C(C)C=CC1=C(C)C(=O)CCC1=O</smiles>

DIV857

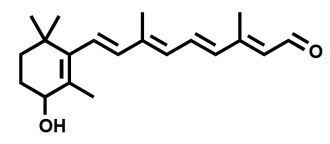

DIV736

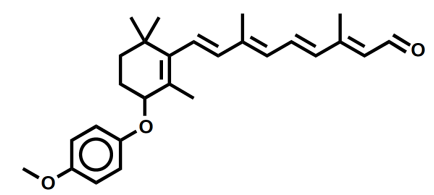

Fig. (1). Molecular structures of tested substances.

\section{RESULTS}

\section{Uptake and Metabolism of Retinoid Derivatives by Keratinocytes and Melanocytes}

RAL, ROL, as well as DIV374, DIV404 and DIV407 gave rise to a high cellular concentration of retinoids in both keratinocytes and melanocytes, i.e. a total of approximately $10^{\prime} 000$ (pmol/mg prot) (Figs. 2-4). As expected, RA was not reduced to its precursors ROL and RAL, the bioconversion of RAL to RA being irreversible (Figs. 2A, 3A). RAL was reduced to ROL and ROL esters in both cells, and was oxidised to significant amounts of RA in keratinocytes only
Arbutin<smiles>OCC1OC(Oc2ccc(O)cc2)[C@H](O)[C@@H](O)[C@@H]1O</smiles>

ARA

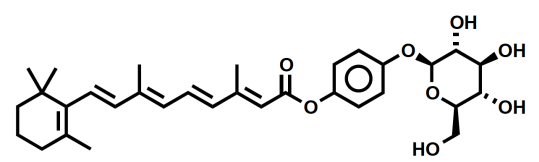

DIV633

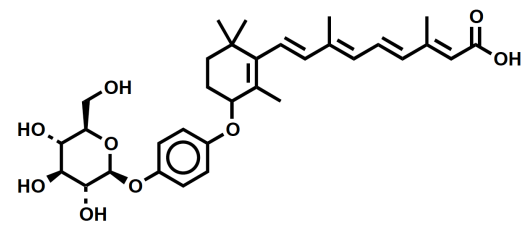

DIV407<smiles>CC(=O)OC1CCC(C)(C)C1=C/C=C(C)/C=C/C=C(C)C(=O)OC(C)(C)C</smiles>

ROL

DIV420

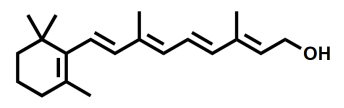

DIV1178

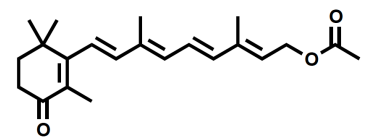

DIV1181
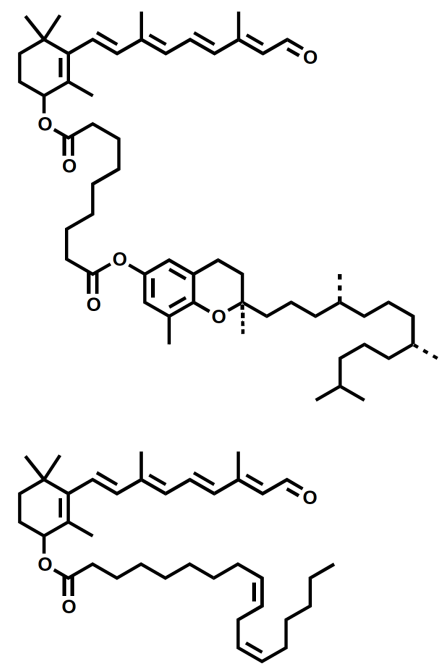

(Figs. 2B, 3B). ROL was esterified to fatty acids in both cells, and was partly oxidised to RAL in melanocytes only (Figs. 2C, 3C). RA and its methyl esters of 4-oxo (DIV408) and 4-hydroxy (DIV419) derivatives were less taken up by the cells, with a total of retinoids of $\approx 1^{\prime} 000(\mathrm{pmol} / \mathrm{mg}$ prot $)$ (Figs. 2A, G, H, 3A, G, H). The esters of 4-oxo RA were marginally reduced to their 4-hydroxy counterparts, whereas the 4-hydroxyderivatives were mostly oxidised to the 4-oxo ones (Figs. 2E, G, H, 3E, G, H). 4-OxoRAL, unlike RAL, was much less taken up by the cells, in particular by melanocytes, and was mostly reduced to 4-oxoROL in keratinocytes, the sum reaching 300 ( $\mathrm{pmol} / \mathrm{mg}$ prot) in keratinocytes and 30 (pmol/mg prot) in melanocytes (Figs. 

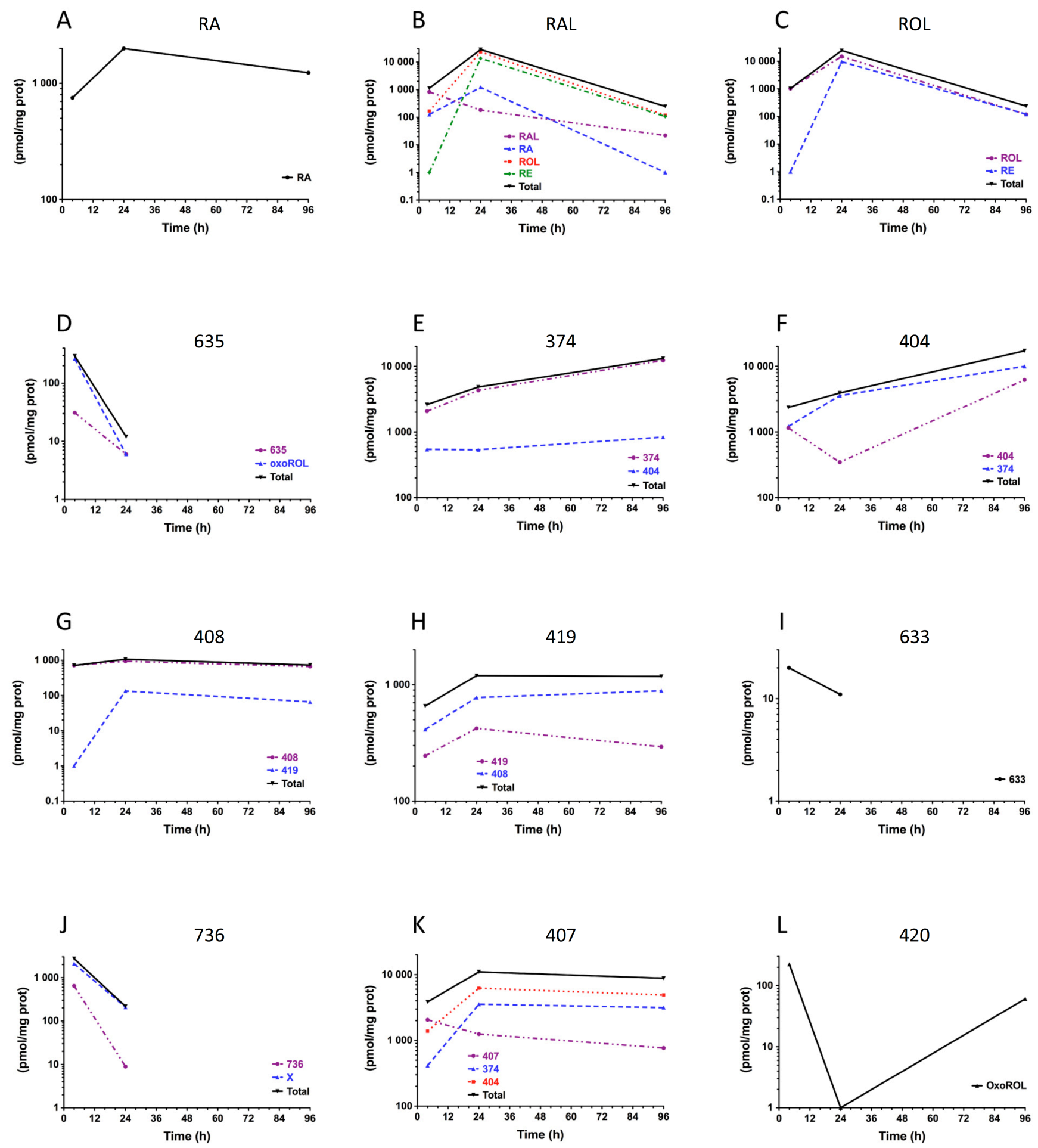

Fig. (2). Uptake and metabolism in BDVII keratinocytes. Retinoids were applied at $10 \mu \mathrm{M}$ for 4, 24 or 96 hours on BDVII keratinocytes, then intracellular retinoids were analysed by HPLC. Applied retinoids, indicated on the top of each graph, were RA (A), RAL (B), ROL (C), 635 (D), $374(\mathbf{E}), 404(\mathbf{F}), 408(\mathbf{G}), 419(\mathbf{H}), 633$ (I), 736 (J), $407(\mathbf{K})$ and $420(\mathbf{L})$. Results, expressed as (pmol retinoid/mg protein), represent the means of duplicate experiments. The whole experiment was repeated twice with a similar pharmacological profile. RE: retinyl esters.

2D, 3D). A hydroquinone derivative of 4-hydroxyretinal (DIV736) was taken up and mostly metabolised to an unidentified metabolite by both cell types (Figs. 2J, 3J). DIV1178 and DIV1181 did not produce detectable retinoids within keratinocytes or melanocytes at $10 \mu \mathrm{M}$; they were then applied at $100 \mu \mathrm{M}$, and at this high concentration
DIV1181 was taken up by both cell types (162 and 329 (pmol/mg prot) at $24 \mathrm{~h}$ for B16 and BDVII, respectively) and converted to DIV857 and unidentified metabolites, whereas DIV1178 was still not taken up by the cells in these conditions (not shown). 
A

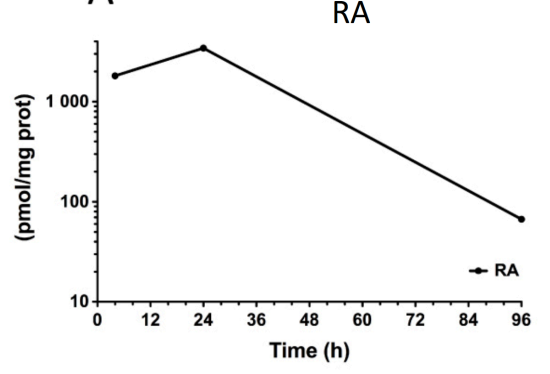

D

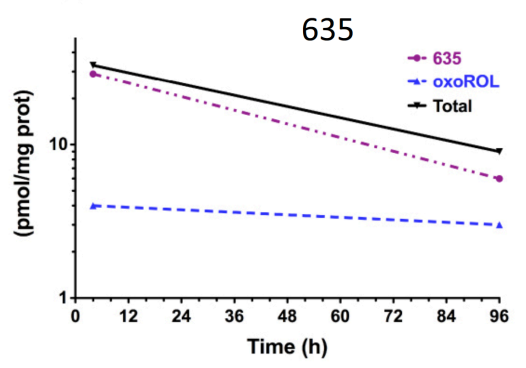

G

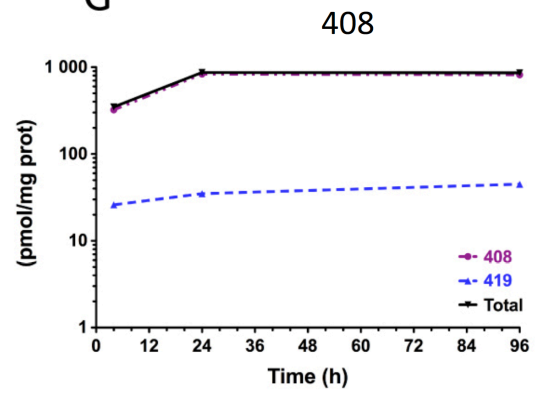

J

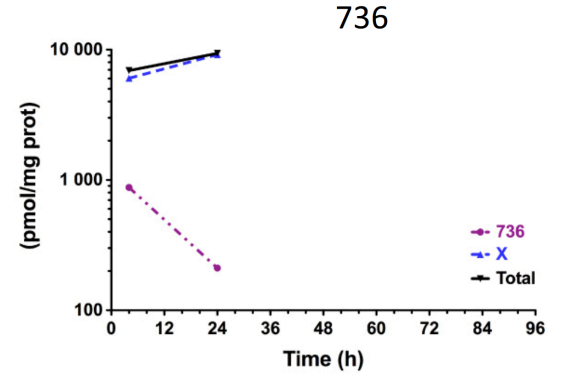

B

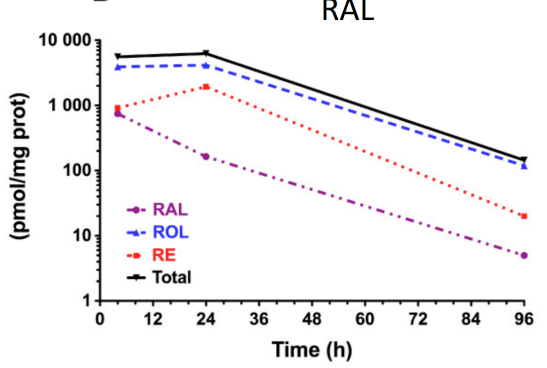

E

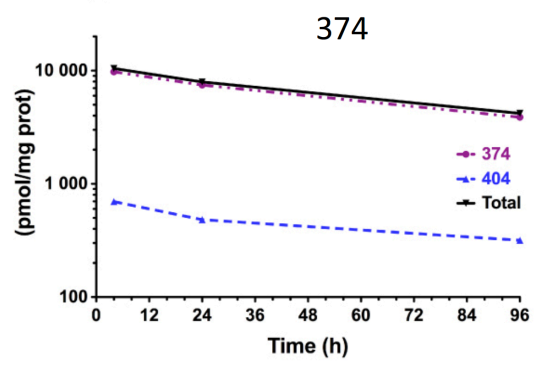

$\mathrm{H}$

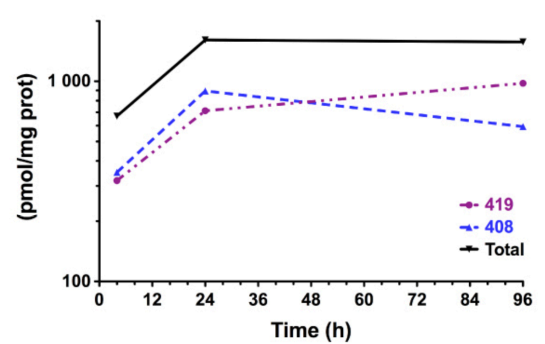

K

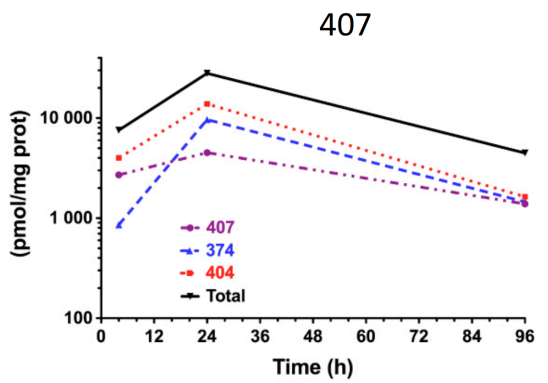

C

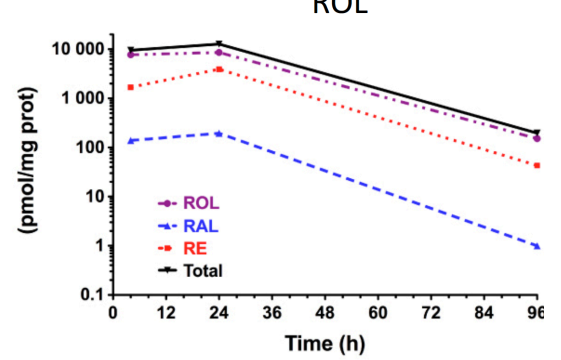

$\mathrm{F}$

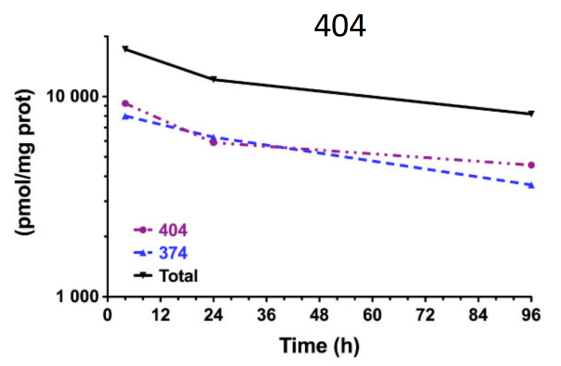

633

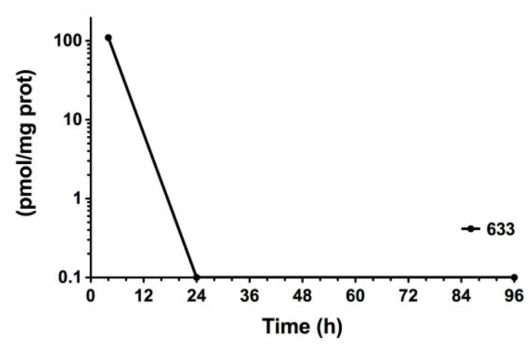

L

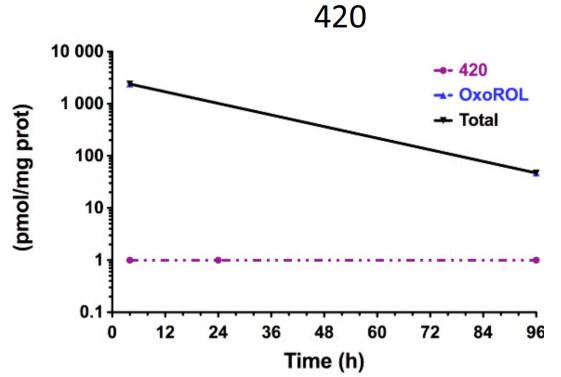

Fig. (3). Uptake and metabolism in B16 melanocytes. Retinoids were applied at $10 \mu \mathrm{M}$ for 4, 24 or 96 hours on B16 melanocytes, then intracellular retinoids were analysed by HPLC. Applied retinoids, indicated on the top of each graph, were RA (A), RAL (B), ROL (C), 635 (D), $374(\mathbf{E}), 404(\mathbf{F}), 408(\mathbf{G}), 419(\mathbf{H}), 633(\mathbf{I}), 736(\mathbf{J}), 407(\mathbf{K})$ and $420(\mathbf{L})$. Results, expressed as (pmol retinoid/mg protein), represent the means of duplicate experiments. The whole experiment was repeated twice with a similar pharmacological profile. RE: retinyl esters. 


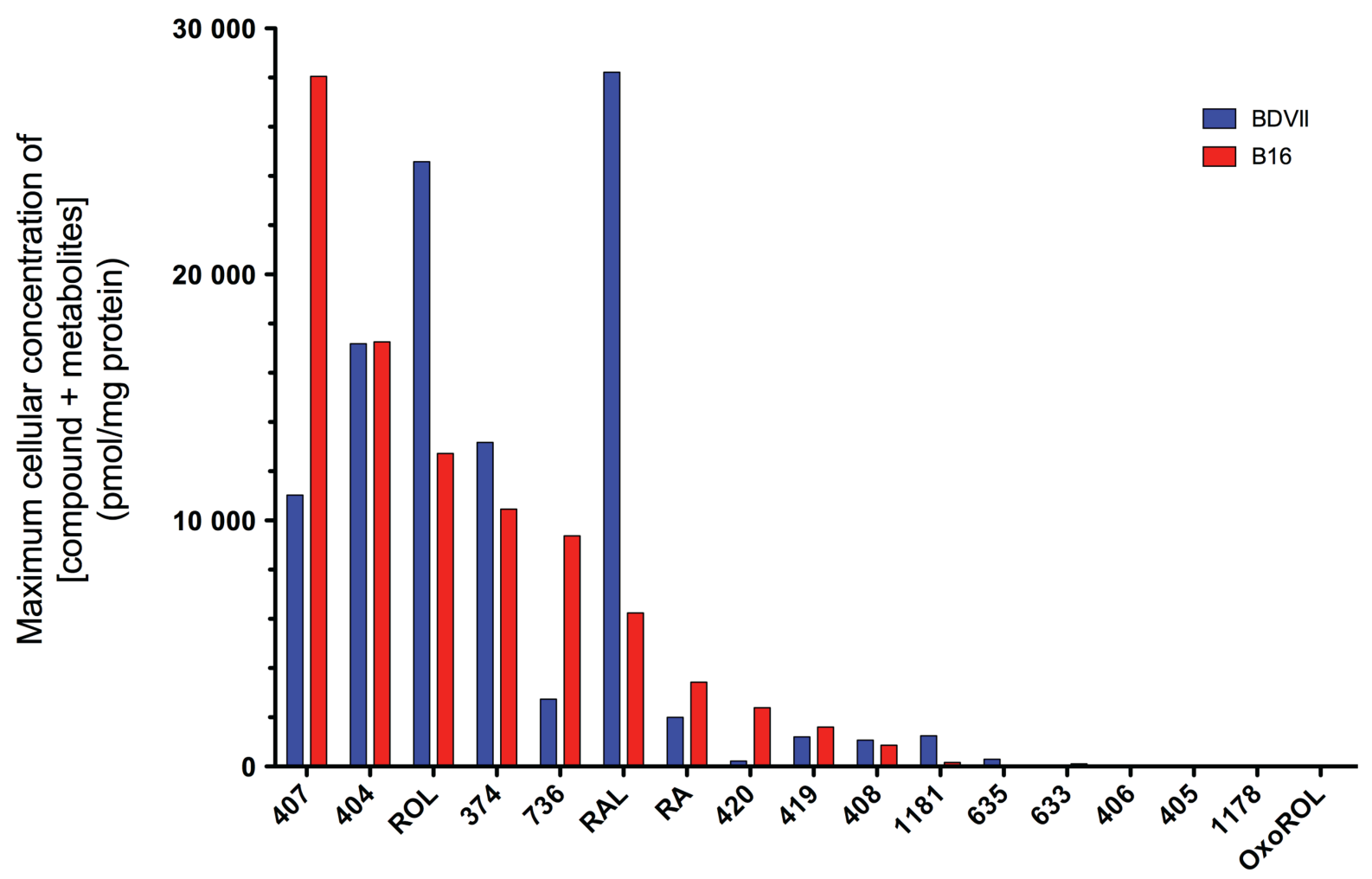

Fig. (4). Maximum total retinoid concentration. The histogram shows the maximum cellular retinoid concentration following incubation with the tested retinoids. Depending on the tested compounds, the maximum concentration is reached at $4 \mathrm{~h}, 24 \mathrm{~h}$, or $96 \mathrm{~h}$. Results, expressed as (pmol retinoid/mg protein), represent the means of duplicate experiments, and where calculated from data shown in Figs. (2, 3).

Table 2. Cell Viability and Depigmenting Parameters

\begin{tabular}{|c|c|c|c|c|c|}
\hline \multirow{2}{*}{ Compound } & \multirow{2}{*}{$\begin{array}{c}\text { BDV II Keratinocytes } \\
\text { IC }_{50}[\text { toxicity] }(\mu \mathrm{M})\end{array}$} & \multicolumn{4}{|c|}{ B16 Melanocytes } \\
\hline & & IC $_{50}[$ toxicity] $(\mu \mathrm{M})$ & $\mathrm{IC}_{50}$ melanin $(\mu \mathrm{M})$ & $\mathrm{IC}_{50}$ [depigmentation] $(\mu \mathrm{M})$ & Pigmentation Index \\
\hline RA & 15 & 5 & 0.06 & 2 & 83 \\
\hline Arbutin & $>100$ & $>100$ & 3 & 40 & $>33$ \\
\hline ARA & 20 & 10 & 0.15 & 0.2 & 67 \\
\hline DIV 00374 & 50 & 30 & 1 & 2 & 30 \\
\hline DIV 00404 & 50 & 10 & 2 & 20 & 5 \\
\hline DIV 00408 & 10 & 50 & 0.4 & 0.5 & 125 \\
\hline DIV 00419 & 20 & 30 & 5 & 7 & 6 \\
\hline RAL & 3 & 2 & 0.3 & 0.4 & 7 \\
\hline DIV 00857 & 10 & 4 & 0.6 & 1 & 7 \\
\hline DIV 00736 & 20 & 20 & 15 & 40 & 1 \\
\hline
\end{tabular}

The pharmacological parameters shown here $\left(\mathrm{IC}_{50}\right.$ and pigmentation indexes) were calculated from concentration-response curves of two separate experiments performed in the same series of cultures. For cell viability the measured parameter was the value for MTT assay (i.e. MTT formazan, or MTTF) and for cellular melanin content the measured parameter was expressed as ( $\mu \mathrm{g}$ melanin/ $\mu \mathrm{mol}$ MTTF) [16]. From the corresponding concentration-responses curves the $\mathrm{IC}_{50}$ s for the toxicity and the depigmentation can be determined. The whole experiments were repeated twice in two separate series of cultures with similar pharmacological profiles, although with different absolute values due to inter-experiment variability. The $\mathrm{IC}_{50} \mathrm{~S}$ and pigmentation indexes however are very comparable from one experiment to another. The pigmentation index is defined as $\mathrm{IC}_{50}$ [toxicity] divided by $\mathrm{IC}_{50}$ (melanin) (see Results for details).

\section{Tolerance Profiles of Retinoid Derivatives in Keratinocytes and Melanocytes}

The MTT assay allows the determination of an $\mathrm{IC}_{50}$ for the toxicity ( $\mathrm{IC}_{50}$ [toxicity]). RAL and its 4hydroxyderivative were the most toxic to both cell cultures with $\mathrm{IC}_{50}$ in the low $\mu \mathrm{M}$ range, then came RA and its esters with $\mathrm{IC}_{50} \mathrm{~s}$ between 5 and $50 \mu \mathrm{M}$ (Table 2). In keratinocytes the $t$-butyl esters of RA derivatives were less toxic than the methyl esters (Table 2). Arbutin was well tolerated in both cells with $\mathrm{IC}_{50} \mathrm{~s}>100 \mu \mathrm{M}$ (Table 2). 

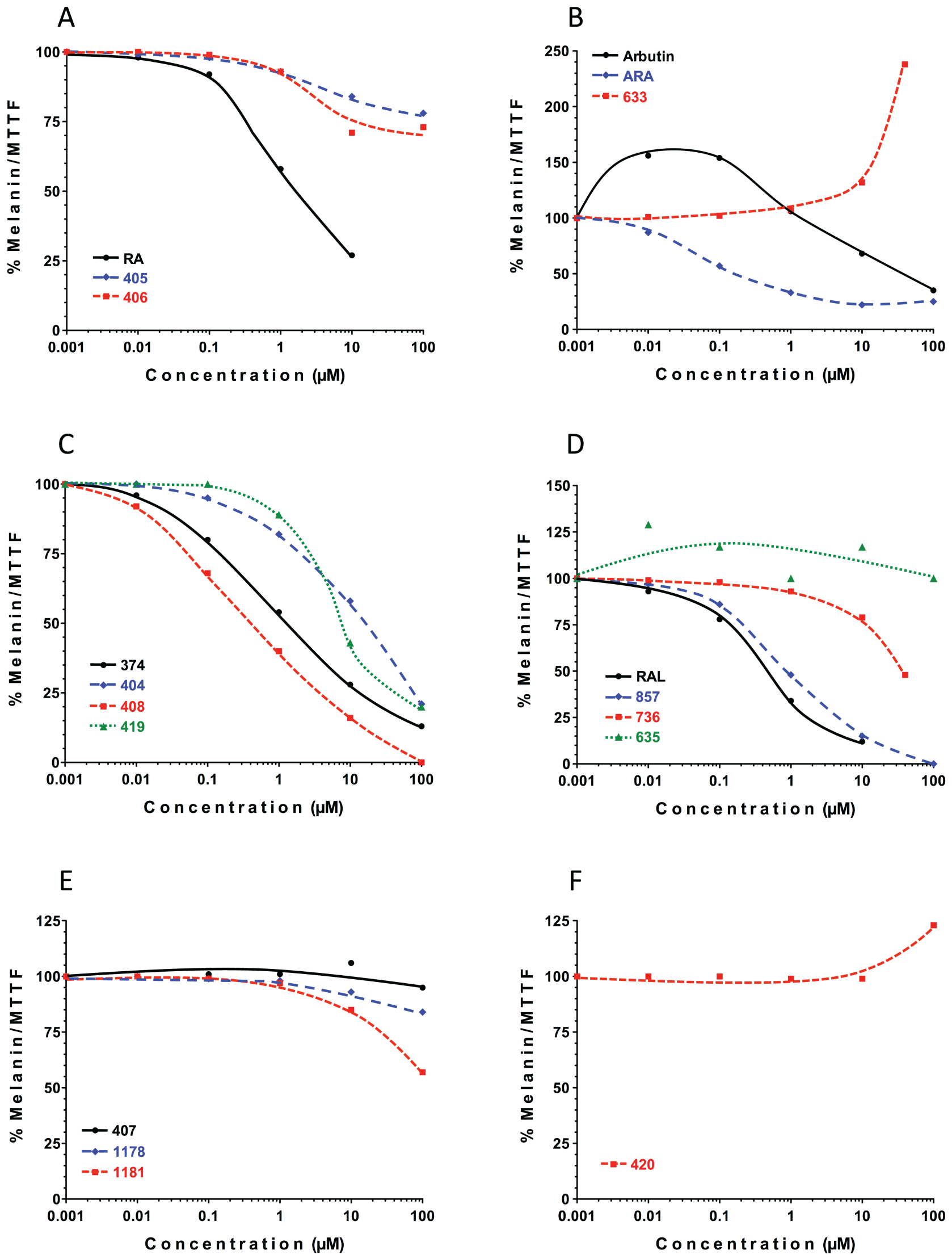

Fig. (5). Effects of retinoids on melanocyte melanin. Retinoids were applied for three consecutive days at various concentrations on B16 melanocytes, then cellular melanin content was determined and MTT assay performed two days following the last treatment. Results, calculated as (mg melanin/mol reduced MTT), are expressed as percentage of the value of vehicle (1\% ethanol), and represent the means of duplicate experiment. The whole experiment was repeated twice with a similar pharmacological profile. 


\section{Depigmenting Potential of Retinoid Derivatives}

To assess the depigmenting potential of the tested compounds, we defined a pigmentation index. This parameter gives an index of the specific action on cellular melanin content. Ideally, a compound that decreases specifically the melanin content in a concentrationdependent manner without affecting the viability of the cells would have a low $\mathrm{IC}_{50}$ for melanin and a much higher $\mathrm{IC}_{50}$ for the toxicity (MTT assay) [16]. We thus define the pigmentation index (PI): $\mathrm{PI} \equiv \mathrm{IC}_{50}$ [toxicity] / $\mathrm{IC}_{50}$ [melanin]. According to the PI, esters of 4-oxoretinoate, arbutin retinoate and retinoic acid are the most interesting compounds, then come RAL and its 4-hydroxyderivatives, which have a strong effect on melanin, but with a narrower therapeutic window due to a lower $\mathrm{IC}_{50}$ [toxicity] (Table 2, Fig. 5). The DOPA oxidase activity of the retinoid derivatives does not parallel the depigmenting activity, except for RAL, indicating that the mechanism by which these compounds decrease the cellular melanin is not mediated by an inhibition of tyrosinase (Table $\mathbf{3}$ ).

Table 3. DOPA Oxidase Activity vs Inhibition of Melanin

\begin{tabular}{|c|c|c|c|}
\hline \multirow[b]{2}{*}{ Compound } & \multirow[b]{2}{*}{$\begin{array}{c}\text { Concentration } \\
(\mu \mathrm{M})\end{array}$} & \multicolumn{2}{|c|}{$\%$ of Vehicle } \\
\hline & & $\underset{\text { MTT }}{\text { Melanin/ }}$ & $\begin{array}{c}\text { DOPA } \\
\text { Oxidase }\end{array}$ \\
\hline RAL & 1 & 34 & 22 \\
\hline DIV857 & 10 & 15 & 116 \\
\hline DIV374 & 10 & 28 & 104 \\
\hline DIV404 & 10 & 58 & 117 \\
\hline DIV405 & 10 & 84 & 102 \\
\hline DIV406 & 10 & 71 & 89 \\
\hline DIV407 & 10 & 106 & 158 \\
\hline DIV408 & 10 & 16 & 161 \\
\hline DIV419 & 10 & 43 & 117 \\
\hline DIV420 & 10 & 99 & 95 \\
\hline DIV1178 & 100 & 84 & 110 \\
\hline DIV1181 & 100 & 57 & 77 \\
\hline
\end{tabular}

DOPA oxidase activity was measured as ( $\mu$ mol oxidised DOPA/min). For each compound the value of DOPA oxidase is indicated as the $\%$ of activity as compared to solvent alone (ethanol 1\%). The indicated values represent the mean of two experiments performed in the same series of cultures. The whole experiment was repeated twice with similar \% values.

\section{DISCUSSION}

Topical RA and its 13-cis isomer (isotretinoin) are used as anti-acne therapeutic agents, whereas RAL is used in cosmetic formulations to slow down skin ageing or to lighten skin pigmentation [19-21]. On the other hand, most, if not all, depigmenting agents target tyrosinase, the enzyme that catalyzes the rate-limiting step of melanogenesis [22]. However, there is a clear discrepancy between the antityrosinase activity in vitro and the ability to lighten the skin in vivo [23].

Although retinoids are not known to be tyrosinase inhibitors, RA and RAL have been shown to potentiate the depigmenting action of other agents such as hydroquinone [6], 4-hydroxyanisole [7] and glycolic acid [8], probably via a distinct mechanism of action. In our study, the conditions leading to a significant decrease of melanin content did not correlate to a decrease of DOPA oxidase activity, except for RAL (Table 3).

The problem with the use of systemic retinoids is their teratogenicity $[24,25]$. However topical retinoids were proved to be safe, since no significant increase of circulating retinoids has been observed following topical retinoids [2629]. Topical RA induces a skin irritation that may lead to cessation of treatment. Topical RAL is quite less irritant and may be used for longer periods of time [30-33]. In this context it is interesting to have at one's disposal a new family of branched retinoids with a potential depigmenting effect, which could be added, alone or in combination, in skin lightening formulations.

The tolerance profile, the uptake and the metabolism of the new retinoid derivatives were analysed in cultured keratinocytes and melanocytes. Most of them were rapidly taken up by the cells. The hydroxyl group at position 4 of the cyclohexenyl cycle was reversibly oxidised into a carbonyl. In the case of 4-oxoretinol, sizable amounts of the compound were found in keratinocytes at $4 \mathrm{~h}$ and $96 \mathrm{~h}$, were it was almost undetectable at $24 \mathrm{~h}$. This could be due to the production of a metabolite not observed in the HPLC chromatogram; alternatively, it is possible that the cellular concentrations of a given compound are quite variable as a function of time. Our data indicate that methyl and $t$-butyl esters of 4-oxoretinoic acid have a good tolerance profile in both cultured keratinocytes and melanocytes and have a specific inhibitory action on cellular melanin in cultured melanocytes, as indicated by a high pigmentation index. This parameter gives a better information on the specific action on melanin, because the MTT assay is a better index of cell viability that the protein content. Indeed, dead cells still have proteins, which may be assayed using the Bradford method, whereas a corresponding MTT assay would give a value close to 0 . Interestingly, 4-hydroxyretinoate esters were not hydrolysed into retinoic acid within the cells, since RA was always under the detection limit of 10 ( $\mathrm{pmol} / \mathrm{mg}$ prot), indicating that these 4-oxoRA esters have an inhibitory action on melanin per se. 4-Oxo- and 4-hydroxy-retinoic acids were not taken up by both keratinocytes and melanocytes, which precluded the analysis of their tolerance profile and depigmenting potential in our in vitro models; in these conditions, if they don't penetrate into cultured melanocytes, they appear as bad candidates for an application as topical agents. This is the same for DIV1178, a 4-hydroxyRAL derivative esterified on the position 4 with a $\delta$-tocopheryl azelate. It is interesting to note that another 4hydroxyRAL ester, DIV1181, was taken up by the cells and hydrolysed to 4-hydroxyRAL (DIV857), indicating a certain selectivity of the endogenous esterase that metabolised DIV1181.

As a conclusion, these retinoid derivatives have a development potential, and could be combined to tyrosinase inhibitors, but randomised controlled clinical trials are now expected to confirm the depigmenting activity of these new retinoids in topical formulations. 


\section{CONFLICT OF INTEREST}

This study was supported by GENDERM.

\section{ACKNOWLEDGEMENTS}

Declared none.

\section{REFERENCES}

[1] Grimes, P.; Nordlund, J.J.; Pandya, A.G.; Taylor, S.; Rendon, M., Ortonne, J.P. Increasing our understanding of pigmentary disorders. J. Am. Acad. Dermatol., 2006, 54, S255-S261.

[2] Sidhu, S.K.; Paul, N.; Sidhu, J.S.; Oakeshott, P. Use of skin lightening creams. Survey in a UK general practice. $B M J, 2011$, $342, \mathrm{~d} 1326$.

[3] Scarpa, A.; Guerci, A. Depigmenting procedures and drugs employed by melanoderm populations. J. Ethnopharmacol., 1987, $19,17-66$

[4] Nnoruka, E.; Okoye, O. Topical steroid abuse its use as a depigmenting agent. J. Natl. Med. Assoc., 2006, 98, 934-939.

[5] Kooyers, T.J.; Westerhof, W. Toxicology and health risks of hydroquinone in skin lightening formulations. J. Eur. Acad. Dermatol. Venereol., 2006, 20, 777-780.

[6] Kligman, A.M.; Willis, I. A new formula for depigmenting human skin. Arch. Dermatol., 1975, 111, 40-48.

[7] Nair, X.; Parab, P.; Suhr, L.; Tramposch, K.M. Combination of 4hydroxyanisole and all-trans retinoic acid produces synergistic skin depigmentation in swine. J. Invest. Dermatol., 1993, 101, 145-149.

[8] Kasraee, B.; Tran, C.; Sorg, O.; Saurat, J.H. The depigmenting effect of RALGA in C57BL/6 mice. Dermatology, 2005, 210 (Suppl 1), 30-34.

[9] Napoli, J.L. Retinoic acid biosynthesis and metabolism. FASEB J., 1996, 10, 993-1001.

[10] Vogel, S.; Gamble, M.V.; Blaner, W.S. Biosynthesis, Absorption, Metabolism and Transport of Retinoids; Springer: Berlin, 1999.

[11] Blomhoff, R.; Blomhoff, H.K. Overview of retinoid metabolism and function. J. Neurobiol., 2006, 66, 606-330.

[12] Sorg, O.; Tran, C.; Carraux, P.; Grand, D.; Barraclough, C.; Arrighi, J.F.; Descombes, P.; Piguet, V.; Saurat, J.H. Metabolism and biological activities of topical 4-oxoretinoids in mouse skin. $J$. Invest. Dermatol., 2008, 128, 999-1008.

[13] Kim, H.; Kim, B.; Um, S.; Lee, J.; Ryoo, H.; Jung, H. Synthesis and in vitro biological activity of retinyl retinoate, a novel hybrid retinoid derivative. Bioorg. Med. Chem., 2008, 16, 6387-6393.

[14] Kasraee, B.; Nikolic, D.S.; Salomon, D.; Carraux, P.; Fontao, L.; Piguet, V.; Gholamhossein, R.; Omrani, G.R.; Sorg, O.; Saurat, J.H. Ebselen is a new skin depigmenting agent that inhibits melanin biosynthesis and melanosomal transfer. Exp. Dermatol., 2012, 21, 19-24.

[15] Sorg, O.; Tran, C.; Carraux, P.; Grand, D.; Hugin, A.; Didierjean, L.; Saurat, J.H. Spectral properties of topical retinoids prevent DNA damage and apoptosis after acute UVB exposure in hairless mice. Photochem. Photobiol., 2005, 81, 830-836.

[16] Kasraee, B.; Hugin, A.; Tran, C.; Sorg, O.; Saurat, J.H. Methimazole is an inhibitor of melanin synthesis in cultured B16 melanocytes. J. Invest. Dermatol., 2004, 122, 1338-1341.
[17] Sorg, O.; Tran, C.; Carraux, P.; Didierjean, L., Saurat, J.H. Retinol and retinyl ester epidermal pools are not identically sensitive to UVB irradiation and antioxidant protective effect. Dermatology, 1999, 199, 302-307.

[18] Winder, A.J. A stopped spectrophotometric assay for the dopa oxidase activity of tyrosinase. J. Biochem. Biophys. Methods, 1994, 28, 173-183.

[19] Gollnick, H.P.; Krautheim, A. Topical treatment in acne current status and future aspects. Dermatology, 2003, 206, 29-36.

[20] Stratigos, A.J.; Katsambas, A.D. The role of topical retinoids in the treatment of photoaging. Drugs, 2005, 65, 1061-1072.

[21] Tran, C.; Kasraee, B.; Grand, D.; Carraux, P.; Didierjean, J.; Sorg, O.; Saurat, J.H. Pharmacology of RALGA, a mixture of retinaldehyde and glycolic acid. Dermatology, 2005, 210 (Suppl 1), 6-13.

[22] Chang, T.S. An updated review of tyrosinase inhibitors. Int. J. Mol. Sci., 2009, 10, 2440-2475.

[23] Solano, F.; Briganti, S.; Picardo, M.; Ghanem, G. Hypopigmenting agents an updated review on biological, chemical and clinical aspects. Pigment Cell Res., 2006, 19, 550-571.

[24] Willhite, C.C.; Dawson, M.I.; Reichert, U. Receptor-selective retinoid agonists and teratogenic activity. Drug. Metab. Rev., 1996 28, 105-119.

[25] Collins, M.D.; Mao, G.E. Teratology of retinoids. Annu. Rev. Pharmacol. Toxicol., 1999, 39, 399-430.

[26] Chen, C.; Jensen, B.K.; Mistry, G.; Wyss, R.; Zultak, M.; Patel, I.H.; Rakhit, A.K. Negligible systemic absorption of topical isotretinoin cream implications for teratogenicity. J. Clin. Pharmacol., 1997, 37, 279-284.

[27] Nohynek, G.J.; Meuling, W.J.; Vaes, W.H.; Lawrence, R.S.; Shapiro, S.; Schulte, S.; Steiling, W.; Bausch, J.; Gerber, E.; Sasa, H., Nau, H. Repeated topical treatment, in contrast to single oral doses, with Vitamin A-containing preparations does not affect plasma concentrations of retinol, retinyl esters or retinoic acids in female subjects of child-bearing age. Toxicol. Lett., 2006, 163, 6576.

[28] Sorg, O.; Kuenzli, S.; Saurat, J.H. Side Effects and Pitfalls in Retinoid Therapy; Informa Healthcare: New York, 2007.

[29] Yu, Z.; Sefton, J.; Lew-Kaya, D.; Walker, P.; Yu, D.; Tang-Liu, D.D. Pharmacokinetics of tazarotene cream $0.1 \%$ after a single dose and after repeat topical applications at clinical or exaggerated application rates in patients with acne vulgaris or photodamaged skin. Clin. Pharmacokinet., 2003, 42, 921-929.

[30] Campanelli, A., Naldi, L. A retrospective study of the effect of long-term topical application of retinaldehyde $(0.05 \%)$ on the development of actinic keratosis. Dermatology, 2002, 205, 146152 .

[31] Didierjean, L.; Tran, C.; Sorg, O.; Saurat, J.H. Biological activities of topical natural retinaldehyde. Dermatology, 1999, 199 (Suppl. 1), 19-24.

[32] Fluhr, J.W.; Vienne, M.P.; Lauze, C.; Dupuy, P.; Gehring, W., Gloor, M. Tolerance profile of retinol, retinaldehyde and retinoic acid under maximized and long-term clinical conditions. Dermatology, 1999, 199, 57-60.

[33] Saurat, J.H.; Didierjean, L.; Masgrau, E.; Piletta, P.A.; Jaconi, S.; Chatellard-Gruaz, D.; Gumowski, D.; Masouyé, I.; Salomon, I. Siegenthaler, G. Topical retinaldehyde on human skin biological effects and tolerance. J. Invest. Dermatol., 1994, 103, 770-774. 